\title{
Generalizability of guidelines and physicians' adherence. Case study on the Sixth Joint National Commitee's guidelines on hypertension Claudio Pedone ${ }^{1}$ and Kate L Lapane ${ }^{* 2,3}$
}

Address: ${ }^{1}$ Centro di Medicina dell'Invecchiamento, Università Cattolica del Sacro Cuore. Roma, Italia, ${ }^{2}$ Center for Gerontology and Health Care Research, Brown University. Providence RI 02912, USA and '3Department of Community Health, Brown University. Providence RI 02912, USA

Email: Claudio Pedone - claudio_pedone@rm.unicatt.it; Kate L Lapane* - kate_lapane@brown.edu

* Corresponding author

Published: 21 July 2003

BMC Public Health 2003, 3:24
Received: 20 December 2002

Accepted: 21 July 2003

This article is available from: http://www.biomedcentral.com/I47I-2458/3/24

(C) 2003 Pedone and Lapane; licensee BioMed Central Ltd. This is an Open Access article: verbatim copying and redistribution of this article are permitted in all media for any purpose, provided this notice is preserved along with the article's original URL.

\begin{abstract}
Background: Clinical practice guidelines (CPG) are thought to be an effective tool in improving efficiency and outcomes of clinical practice. Physicians' adherence to guidelines is reported to be poor. We evaluated the relationship between generalizability of guidelines on hypertension and physicians' adherence to guidelines' recommendations for pharmacological treatment.

Methods: We used the Sixth Joint National Committee's (JNC VI) guidelines on hypertension to evaluate our hypothesis. We evaluated the evidence from controlled clinical trials on which the JNC VI bases its recommendation, and compared the population enrolled in those trials with the American hypertensive population. Data on this population came from the National Health and Nutritional Examination Survey III.

Results: Twenty-three percent of the NHANES population had a diagnosis of hypertension, $11 \%$ had hypertension requiring drug treatment according to the JNC VI. Only half of the population requiring treatment would have been enrolled in at least two trials. Rate of adherence to CPG was $69 \%$. We found a weak association between generalizability and physicians' adherence to guidelines. Baseline risk was the major determinant of the decision to treat.
\end{abstract}

Conclusion: JNC VI guidelines may not be generalizable to their target population. We found a relatively poor adherence rate to these guidelines. Failing of completely taking into account the clinical characteristics of the patients may be partly responsible for this lack of adherence.

\section{Background}

Guidelines are "systematically developed statements to assist practitioner and patient decisions about appropriate health care for specific clinical circumstances".[1] Guidelines seem to be effective in improving the processes and outcomes of care, [2] and are being used to describe appropriate care based on scientific evidence.[3] Another proposed use of guidelines is for profiling and resource utilization reviews.[4]
Despite evidence of effectiveness and widespread implementation efforts, adherence to guidelines is variable and generally poor.[5-7] The factors involved in a physician's adherence to guidelines have been extensively studied. Lack of familiarity and inertia to previous practice, characteristics of the health care professional and of the practice setting, physician perception of guidelines' usefulness, incentives, regulation and patient-related factors are common barriers to guideline adherence. [8-10] The quality of 
Table I: Recommendation of the JNC VI according to blood pressure and presence of additional risk factors.[17]

\begin{tabular}{ll}
\hline Blood pressure* & Recommendation \\
\hline High normal & \\
Group risk** A & Lifestyle modification \\
Group risk B & Lifestyle modification \\
Group risk C & Drug therapy \\
Stage I & Lifestyle modification (up to I2 months) \\
Group risk A & Lifestyle modification (up to 6 months) \\
Group risk B & Drug therapy \\
Group risk C & \\
Stage $2 / 3$ & Drug therapy \\
Group risk A & Drug therapy \\
Group risk B & Drug therapy \\
Group risk C & \\
\hline
\end{tabular}

\footnotetext{
* High normal: 130-139/85-89 mmHg. Stage I: 140-159/90-99 mmHg. Stage 2/3: $\geq 160 / 100$. ** Group risk A: no risk factors (smoke, dyslipidemia, male gender, age $\geq 60$ years, family history) or target organ disease (cardiovascular diseases, renal failure) or diabetes mellitus; Group risk B: at least one risk factor with no target organ disease or diabetes mellitus; Group risk C: target organ disease or diabetes mellitus.
}

the guidelines and the clarity and specificity of their recommendations seems also to play an important role.[11]

Problems related to the generalizability of clinical practice guidelines, especially for pharmacological interventions, have received much less attention in the medical literature. This could be an issue because intervention guidelines should base their recommendations on scientific evidence from randomized clinical trials. [12] While randomized controlled clinical trials are considered the gold standard for evaluating the efficacy of pharmacological interventions, [13] their generalizability is often questionable, mostly because of stringent inclusion and exclusion criteria imposed. $[14,15]$ This is particularly true for special populations, such as elderly people, who are systematically excluded from clinical trials.[16]

We hypothesized that the limited generalizability of the evidence on which guidelines are based may reduce physicians' adherence to them. We performed a case study on guidelines to lower blood pressure to test the hypothesis that physicians' adherence is lower in groups of people to whom guidelines are not generalizable.

\section{Methods}

\section{Clinical practice guidelines recommendations}

For this study, we used the JNC VI guidelines issued by the National Heart, Blood and Lung Institute, and endorsed by the American Medical Association along with other 44 US organizations.[17] The contributing team members reviewed the relevant articles in English language published since 1992 to gather scientific evidence. The data were synthesized into recommendations by consensus of the executive committee.
The JNC VI categorizes blood pressure levels as optimal $(<120 / 80 \mathrm{mmHg})$, normal $(<130 / 85 \mathrm{mmHg})$, and high normal (130-139/85-90 $\mathrm{mmHg})$. Hypertension is classified as stage 1 (140-159/90-99 $\mathrm{mmHg})$, stage 2 (160$179 / 100-109 \mathrm{mmHg}$ ) or stage 3 ( $\geq 180 / \geq 110 \mathrm{mmHg}$ ). The recommendations for treatment are based on both hypertension stage and risk for category, and are reported in table 1.

\section{Conceptual definition of the study population}

The population of this study is composed of people who should be receiving drug treatment according to the guidelines of the JNC VI (see Table 1). For the analysis of the characteristics of people with or without a prescription of an anti-hypertensive drug, we also required that a physician diagnosed the hypertension.

\section{Operational definition of the study population}

Information on the US hypertensive population was obtained from the National Health and Nutrition Examination Survey III (NHANES III). This study was designed to provide national estimates of health and nutritional estimates of health status of the community-dwelling population of the United States. Eighty-nine survey locations were randomly divided into two sets, that were allocated to different study period. To obtain reliable estimates of health statistics in ethnic minorities as well as on extreme age groups (children and elderly), these groups were oversampled. NHANES includes data on 33,994 persons aged 2 months or older. For the present study, we considered only the adult population (age $\geq 17$ years). All participants had blood pressure measurements obtained during the household interview and during the examination visit using a mercury sphygmomanometer according to the standardized protocol recommended by 
Table 2: Trials on diuretics and/or $\beta$-blockers on which the recommendation of the JNC VI are based.

\begin{tabular}{|c|c|c|c|c|c|c|c|}
\hline & \multicolumn{3}{|c|}{ Eligibility criteria } & \multicolumn{4}{|c|}{ Exclusion criteria* } \\
\hline & Age (years) & Gender & Blood pressure ${ }^{* *}(\mathrm{mmHg})$ & $\begin{array}{l}\text { Myocardial } \\
\text { infarction }\end{array}$ & Stroke & Heart failure & $\begin{array}{c}\text { Renal } \\
\text { impairment }\end{array}$ \\
\hline VA-NHBLI [36] & $35-55$ & Males & DBP: 85-105 & Excluded & Excluded & Excluded & Excluded \\
\hline HDPF [37] & $30-69$ & Both & $\mathrm{DBP} \geq 90$ & Included & Included & Included & Included \\
\hline Oslo [45] & $40-50$ & Male & SBP: $145-180 \mathrm{DBP}<110$ & Excluded & Excluded & Excluded & Excluded \\
\hline Australia [43] & $30-70$ & Both & DBP: $95-110$ SBP<200 & Excluded & Excluded & Included & Included \\
\hline $\operatorname{MRC}[40]$ & $35-64$ & Both & DBP: $90-109$ & Included & Included & Included & Included \\
\hline VA I [34] & $<70$ & Male & DBP: $115-129$ & Included & Included & Included & Included \\
\hline VA II [35] & $<70$ & Male & DBP: 90-114 & Included & Included & Included & Included \\
\hline PHS [44] & $<55$ & Both & DBP: $90-114$ & Excluded & Excluded & Excluded & Excluded \\
\hline HSCSG [33] & $<75$ & Both & SBP: |40-220 DBP: 90-II5 & Included & Included & Included & Excluded \\
\hline Barraclough [32] & $56-69$ & Both & DBP: $100-120$ & Included & Included & Included & Included \\
\hline Carter [38] & $<80$ & Both & $\mathrm{BP} \geq 160 / 110$ & Included & $\begin{array}{c}\text { Must have one in } \\
\text { the previous } 3 \\
\text { months }\end{array}$ & Excluded & Excluded \\
\hline EWPHE [39] & $\geq 60$ & Both & DBP: $90-119$ SBP: $160-239$ & Included & Included & Excluded & Excluded \\
\hline Coope [42] & $60-79$ & Both & $\mathrm{DBP} \geq 105 \mathrm{SBP} \geq 170$ & Excluded & Excluded & Excluded & Excluded \\
\hline$M R C-O$ [29] & $65-75$ & Both & DBP<। I5 SBP: $160-209$ & Included & Included & Excluded & Excluded \\
\hline SHEP [4I] & $\geq 60$ & Both & DBP<90 SBP: $160-219$ & Excluded & Excluded & Excluded & Excluded \\
\hline STOP [30] & $70-84$ & Both & DBP: $90-120$ SBP: $180-130$ & Included & Included & Included & Included \\
\hline
\end{tabular}

* We considered only these exclusion criteria because they are the most important factors influencing the base line risk in hypertensive people $* *$ SPB: Systolic Blood Pressure; DBP: Diastolic Blood Pressure

the American Heart Association, [18] which is similar to the one recommended by the JNC VI.[19] We used the mean of three measurements to determine extent of hypertension. Because of the variable time between the household interview and the examination visit, we only considered the blood pressure measurements taken during the household interview.

We could not establish from the NHANES data the length of time lifestyle modification (diet, exercise) had been tried. Therefore, we decided to focus only on people for whom the JNC VI suggest drug therapy as a first option (people with cardiovascular diseases or target-organ damage or diabetes mellitus, or people with stage 2 or stage 3 hypertension). To identify such people, we used the blood pressure measurements (average of three measurements), self-reported history of cardiovascular disease or diabetes, and the measurement of serum creatinine $(>2 \mathrm{mg} / \mathrm{dl})$ indicating impaired renal function. Our definition does not take into account those with a diagnosis of hypertension but with normal blood pressure levels. We decided to exclude these people from our population because we were unable to evaluate if the prescription was in line with the JNC VI indications in the absence of an uncontrolled blood pressure measurement.

\section{Conceptual definition of generalizability}

Generalizability is defined as the extent to which the findings obtained on a specific sample can be applied to the target population.[20] This definition does not imply that all the characteristics of the sample should be similar to those of the target population, although it is intuitive that lack of representativeness in the study sample affects generalizability. Since the objective of the study was to analyze the effects of generalizability on adherence to guidelines, we decided to focus on the demographic and clinical characteristics that are most likely to influence the decision to treat, that in our specific case are those related to the risk/benefit ratio of using anti-hypertensive drugs. We compared the population that was included in the trials on which the JNC VI recommendations are based with the US hypertensive population. We only considered controlled clinical trials because recommendations were mostly based on the evidence from these studies and from meta-analyses of these studies. To evaluate the generalizability, we used the following criteria for eligibility in the trials: age, gender, and blood pressure levels at the moment of the admission in the study. The exclusion criteria considered were history of myocardial infarction (MI), heart failure (HF), stroke, and renal impairment because these target organ diseases increase the risk of poor outcomes in hypertensive people and are frequently used as inclusion/exclusion criteria in clinical trials. In some instances, it was not clear from the methods section of the trials if the presence of one of these diagnoses resulted in the exclusion from the study. In these cases, we used a conservative approach and the variable was not considered as exclusion criteria (Table 2).

\section{Operational definition of generalizability}

According to the JNC VI, diuretics and beta-blockers should be used as first line pharmacologic therapy to treat 
hypertension.[17] We identified the clinical trials on which this recommendation was made. First, we calculated the proportion of hypertensive people in the NHANES population that would have been eligible for the trial on the basis of their age, gender and blood pressure measurements. Second, we calculated the proportion of people that would have been excluded because of a history of MI, stroke, HF or renal failure. Third, we calculated the resulting proportion of people to which the trial is generalizable. Finally, we calculated the proportion of people to which the results of at least two trials were generalizable. We decided to use two trials because we felt that the results of only one trial were not sufficient to evaluate the effects of a treatment. This is also in line with Food and Drugs Administration's regulation requiring the evidence from at least two randomized clinical trials to establish a drug's efficacy.

\section{Conceptual definition of adherence to guidelines}

We considered the prescription of any anti-hypertensive medication as an indicator of physician's adherence to guidelines. Although the JNC VI indicates diuretics and $\beta$ blockers as first line therapy, we decided to include all the prescriptions in our definition because different drugs are allowed or even suggested in particular situations.

\section{Operational definition of adherence to guidelines}

To exclude people that had unrecognized hypertension, we calculated an adherence rate only in those people who were told by their doctor that they were hypertensive. We used the self-reported prescription of an anti-hypertensive medication to measure the physicians' adherence to guidelines. This approach was chosen instead of using the actual use of antihypertensive medications to avoid the confounding effect due to participants' lack of compliance to medical directives.

\section{Analytic plan}

We calculated the proportion of people to which each trial was generalizable, as well as the proportion of people that would have been included in at least two trials. We estimated the rate of adherence to guidelines, and compared the socio-demographic (age, gender, ethnicity) and clinical (diagnosis of MI, angina, HF, stroke, diabetes, renal impairment, chronic obstructive pulmonary disease) characteristics of people according to whether they were in the group for which the guidelines were followed or not. We also estimated the association of generalizability with adherence to guidelines using an odds ratio (OR). A multiple logistic regression model provided an estimate of the association between generalizability and adherence corrected for demographic and clinical variables.

We evaluated the rate of adherence to guidelines in each of the different risk categories identified by the JNC VI
(Table 1) as requiring anti-hypertensive drugs. The risk factors taken into account to assign people to each risk category were gender (male), age $\geq 60$ years, current smoking, parent with cardiovascular disease before the age of 50, self-reported diagnosis of hypercholesterolemia, and diabetes mellitus or target organ disease.

Among people that had a prescription of an anti-hypertensive medication and that were actually taking a drug, we analyzed the prevalence of use of diuretics, $\beta$-blockers, ACE-inhibitors, calcium antagonists, and $\alpha$-blockers. We evaluated the use of these drugs both in combination and used as mono-therapy.

The data reported are weighted proportions using the applicable weights.[21] The calculation of the standard errors was performed taking into account the non-random sampling strategy of NHANES III. All analyses were performed using SAS ${ }^{\mathrm{TM}}$ Version 8 (SAS Inc., Cary NC) and SUDAAN $^{\mathrm{TM}}$ Version 7.5.6 (RTI, Research Triangle Park, NC).

\section{Results}

The JNC VI recommends the use of diuretics or $\beta$-blockers as first line therapy in hypertension on the basis of the results of two meta-analyses.[22,23] We found some differences in the studies included in these meta-analyses: Psaty et al. did not include some of the studies that were used by MacMahon et al., because of the use of multiple interventions, [24] the use of drugs different than diuretic of $\beta$-blockers, $[25,26]$ or because the study directly compared diuretics to $\beta$-blockers. [27] Furthermore, Psaty et al. included 3 studies that had not been published at the time when MacMahon et al. published their results.[28-30] For these reasons, we used the trials included in the metaanalysis by Psaty et al. We were unable to retrieve information from a small study $(\mathrm{n}=91)$ performed in Japan [31] that was used by Psaty et al. The final number of studies considered was 16.[29,30,32-45]

Table 2 shows the inclusion and exclusion criteria in the trials considered. While most trials had advanced age as exclusion criteria, seven enrolled people aged $>70$ years. The majority of these trials included people with diastolic hypertension, typically with diastolic blood pressure around $90-120 \mathrm{mmHg}$. Myocardial infarction was an exclusion criterion in 6 trials, stroke in 6 trials, HF in 8 trials, and renal failure in 9 trials.

The Adult Survey section of the NHANES III had information on 20,050 participants. About $23 \%$ of this population had a diagnosis of hypertension, and of these $11 \%$ had hypertension requiring treatment according to the recommendations of the JNC VI. The proportion of people with a diagnosis of hypertension but not included in 
Table 3: Generalizability of the individual trials to the hypertensive population.

\begin{tabular}{lccc}
\hline & \% of the pop. eligible* for trial & $\begin{array}{c}\text { \% of the eligible pop. that would be } \\
\text { excluded** }\end{array}$ & $\begin{array}{c}\text { \% of the pop. to which the trial is } \\
\text { generalizable }\end{array}$ \\
\hline VA-NHBLI [36] & 9.7 & 14.1 & 8.3 \\
HDPF [37] & 28.8 & 0 & 28.8 \\
Oslo [45] & 3.3 & 10.6 & 2.9 \\
Australia [43] & 18.1 & 5.7 & 17.1 \\
MRC [40] & 21.0 & 0 & 21.0 \\
VA I [34] & 0.4 & 0 & 0.4 \\
VA II [35] & 18.9 & 0 & 18.9 \\
PHS [44] & 18.5 & 9 & 16.9 \\
HSCSG [33] & 1.2 & 1.1 & 1.2 \\
Barraclough [32] & 11.0 & 0 & 11.0 \\
Carter [38] & 2.6 & 25 & 1.8 \\
EWPHE [39] & 37.4 & 22.3 & 32.8 \\
Coope [42] & 14.2 & 22.1 & 1.1 \\
MRC - O [29] & 14.8 & 9.7 & 13.2 \\
SHEP [4I] & 22.0 & 26.5 & 16.2 \\
STOP [30] & 2.1 & 3.2 & 2.1
\end{tabular}

* Eligibility criteria shown in table 2. People with hypertension and controlled blood pressure was excluded from the analysis. ** Exclusion criteria shown in table 2.

our population because they had normal blood pressure was $17 \%$. In this subgroup of people, $62 \%$ reported a prescription of an anti-hypertensive medication. In our study population, $4.1 \%$ had stage $2 / 3$ hypertension with no other risk factors; $39.2 \%$ had stage $2 / 3$ hypertension with at least one risk factor, $17.3 \%$ had high normal blood pressure and target organ damage or diabetes, $26.1 \%$ had stage 1 hypertension with target organ damage or diabetes, and $13.3 \%$ had stage $2 / 3$ hypertension with target organ diseases or diabetes. The mean age was 63 years (range $17-90$ ), 50\% were women and $82 \%$ were white.

Table 3 shows the proportion of the people with hypertension requiring drug treatment according to the JNC VI. The first column reports the percent of the total hypertensive population that would be eligible for each trial according to their age, gender and blood pressure levels. The second column reports the proportion of people that would have been excluded from the trials because of MI, stroke, HF, and renal impairment. Finally, we report the proportion of the hypertensive population that would potentially be enrolled in each trial. We observe a marked variability in the generalizability of the trials, ranging from $0.4 \%$ (VA I) to $33 \%$ (EWPHE). Only four trials were generalizable to more than $20 \%$ of the hypertensive population. Such poor generalizability appeared to be a function of the eligibility rather than of the exclusion criteria. Most people were not eligible because high levels of diastolic blood pressure that were required to be enrolled in the trials, as well as of age limits for inclusion in the trials. Overall, the proportion of people in our sample that would potentially have been enrolled in at least 1 trial was $57.5 \%$, and $52.5 \%$ would potentially be enrolled in at least 2 trials.

About $60 \%$ of hypertensive people requiring drug treatment according to the JNC VI had been told by a doctor that they had hypertension. Of these, 69\% reported having a current prescription for anti-hypertensive drugs. Table 4 compares the characteristics of people reporting a prescription for anti-hypertensive drugs vs. those not reporting a prescription for an antihypertensive medication. People in the first group were more likely to be elderly $(42.3 \%$ treated vs. $16.4 \%$ not treated). Fifty-six percent of diagnosed hypertensives who were treated were women compared to $43.2 \%$ who were not treated. The distribution of race/ethnicity varied slightly according to treatment with a lower prevalence of whites among the treated group ( $81.5 \%$ vs. $85.5 \%$ not treated). Stroke, HF and renal failure were associated with more than a doubling of the probability of having a prescription for antihypertensive drugs. The prevalence of MI was $23 \%$ among those with prescription, and $15.5 \%$ among those without a prescription. Diabetes $(28.8 \%$ vs. $25.9 \%)$ and chronic obstructive pulmonary disease $(16.2 \%$ vs. $13.4 \%)$ were not associated with treatment. We observed a lower prevalence of people that would have been enrolled in at least two trials in the group receiving drug treatment. People similar to the population enrolled in clinical trials were $30 \%$ less likely to receive any hypertensive treatment, although the confidence intervals were wide (OR: 0.7, 95\% CI: $0.4-1.3$ ). 
Table 4: Comparison of the characteristics of people with diagnosed hypertension who were told to take antihypertensive medications vs. people not told.

\begin{tabular}{|c|c|c|c|c|}
\hline & Treatment prescribed $\%$ & Treatment not prescribed \% & Odds Ratio (95\% C. I.) & $\begin{array}{c}\text { Adjusted Odds Ratio } \\
\text { (95\% C. I.) }\end{array}$ \\
\hline Age $\geq 70$ years & 42.3 & 16.4 & $3.8(2.6-5.4)$ & $4.1(2.9-6.0)$ \\
\hline Women & 55.8 & 43.2 & $1.7(1.1-2.5)$ & $1.5(1.0-2.5)$ \\
\hline \multicolumn{5}{|l|}{ Race / Ethnicity } \\
\hline White & 81.5 & 85.5 & 1.0 & 1.0 \\
\hline Black & 16.3 & 12.0 & $1.4(0.9-2.2)$ & $1.7(1.1-2.6)$ \\
\hline Other & 2.1 & 2.2 & $1.0(0.2-4.3)$ & $0.9(0.2-4.1)$ \\
\hline Myocardial infarction & 23.0 & 15.5 & $1.6(1.0-2.8)$ & $1.5(0.9-2.7)$ \\
\hline Stroke & 13.1 & 6.0 & $2.3(1.3-4.20)$ & $1.9(0.9-4.1)$ \\
\hline Heart failure & 16.3 & 8.3 & $2.2(1.1-4.2)$ & $2.1(0.8-5.5)$ \\
\hline Renal impairment & 4.8 & 1.7 & $3.0(0.7-13.6)$ & $2.5(0.4-14.6)$ \\
\hline Diabetes & 28.9 & 25.9 & $1.2(0.7-1.9)$ & $1.4(0.8-2.5)$ \\
\hline Chronic pulmonary disease & 13.4 & 16.2 & $0.8(0.4-1.6)$ & $0.7(0.3-1.1)$ \\
\hline Physical impairment & 13.3 & 11.6 & $1.2(0.7-2.1)$ & $0.6(0.3-1.1)$ \\
\hline Eligible in 2 or more trials & 53.3 & 62.4 & $0.7(0.4-1.3)$ & $1.2(0.6-2.8)$ \\
\hline
\end{tabular}

After adjustment for demographic and clinical characteristics, the direction of the association between generalizability and treatment was reversed, with people similar to those included in clinical trial being $20 \%$ as likely to receive an antihypertensive medication than those without such characteristics (OR: 1.2; 95\% CI: $0.6-2.8$ ). The estimated association for the other variables was unchanged, except for physical impairment, which after the adjustment was associated with a decreased probability of being prescribed an antihypertensive drug.

Figure 1 shows the rate of adherence to guidelines among the group to which the trials were generalizable compared to those to whom the trials were not generalizable. Adherence to guidelines was in general higher in the groups with target organ diseases or diabetes mellitus. In the group with high normal blood pressure and target organ disease, we found nobody that would have been included in at least two trials. In the other groups, generalizability had little effect on the adherence rate. People in the group to which the trials can be generalizable had a lower prevalence of treatment, although the differences were small. An exception was the group with stage $2 / 3$ hypertension and at least 1 risk factor, in which people that would have been enrolled in at least two trials were more likely to be treated ( $81 \%$ vs. $75 \%)$.

Of hypertensive people who had both a diagnosis and a prescription made by their physician, $76 \%$ were actually taking any medication at the time of the interview. Table 5 shows the type of treatment reported. When we considered only drugs used in mono-therapy, we found that calcium channel blockers were the drugs most frequently used $(15 \%)$, followed by diuretics and ACE-inhibitors
(11\%). $\beta$-blockers were taken as mono-therapy by $9 \%$ of persons. Considering any prescription, diuretics were the drugs most commonly used $(41.5 \%)$, followed by calcium channel blockers (38.8\%) and ACE-inhibitors (31.6\%), and $\beta$-blockers (26.1\%).

\section{Discussion}

The JNC VI bases its recommendations on the drug treatment of hypertensive people on a convincing scientific basis. The pooled results of the trials on diuretics and/or $\beta$-blockers considered as the basis for the guidelines show a clear reduction in stroke, $[22,46]$ congestive HF and total cardiovascular mortality.[22,23,46] Nonetheless, differences between the populations studied and the populations actually receiving the medications pose the problem of the generalizability of the results. Using only few eligibility/exclusion criteria, we found that the generalizability of the individual trials was poor. Forty percent of the population would not have been enrolled in at least one trial, and half of the population was not eligible for at least two trials.

The JNC VI extends its recommendation to people with blood pressure levels generally lower than the population included in the trials. In one of the groups for which treatment is recommended by the JNC VI (i.e. people with high normal blood pressure and target-organ disease or diabetes), we found nobody that would be included in at least two trials. This is problematic. Since characteristics of the population translate into different baseline risks, the absolute benefits observed in trials may be different than those observed in the general population.[47] While it is arguable that clinical trials, excluding people with substantial comorbidity, underestimate the real benefit of the 


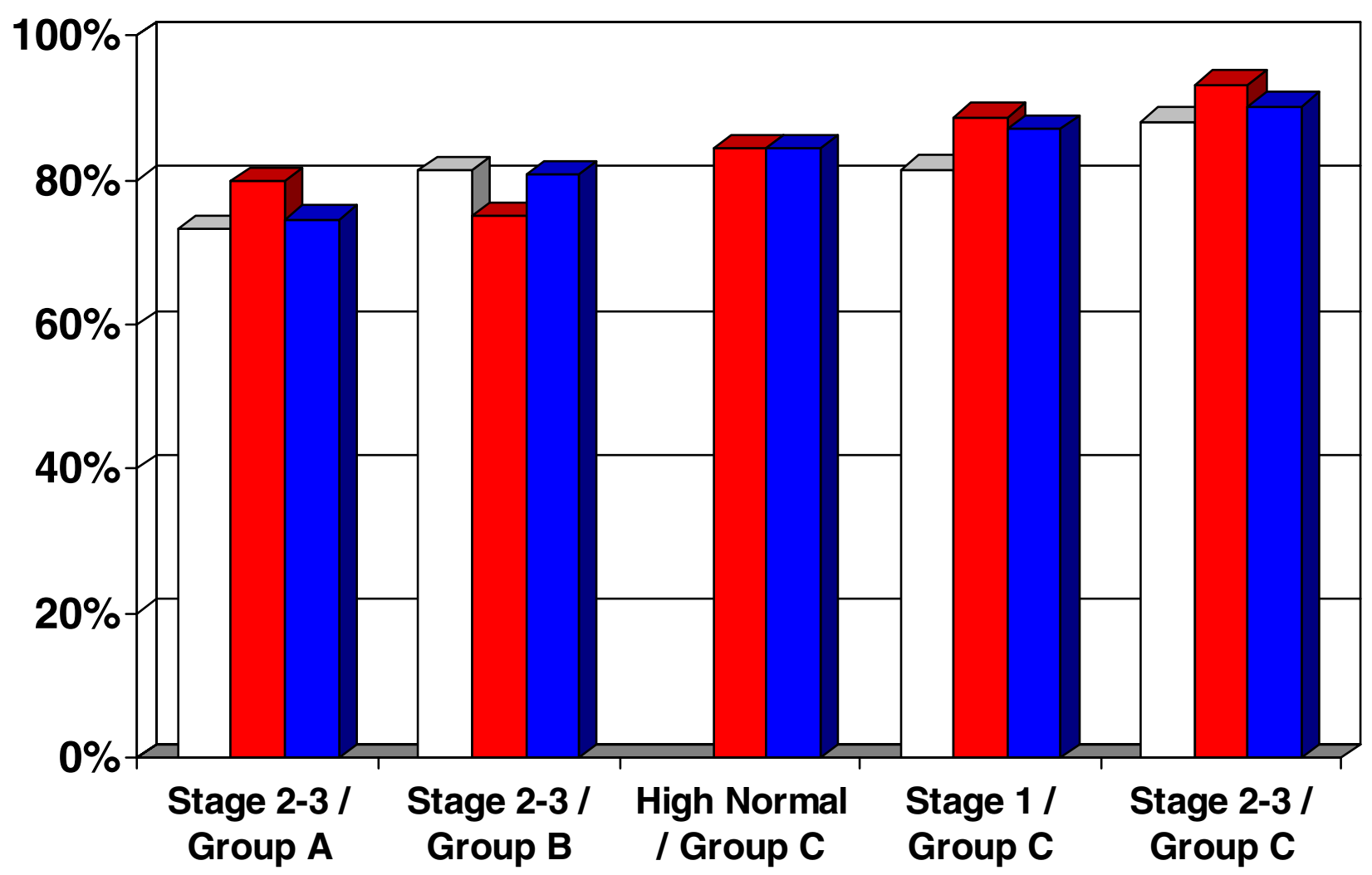

\section{Trials generalizable $\square$ Trials not generalizable $\square$ Total}

Figure I

Proportion of people receiving drug treatment according to trials' generalizability. Stratified by blood pressure and risk category as defined in table I.

Table 5: Use of anti-hypertensive drugs among people who had a medication prescribed by their doctors and that were taking the drug at the time of the interview.

\section{Monotherapy}


treatment, [48] any generalization to a population with a baseline risk level different the one studied in an individual trial needs to be evaluated. Furthermore, since the risk of adverse drug reactions increases with the underlying clinical severity, [49] it is seldom easy to estimate the real risk/benefit ratio when data are not available in a specific population.

Our data show that a substantial proportion of people (30\%) with a diagnosis of hypertension and that should receive treatment according to the JNC VI guidelines have not been prescribed any antihypertensive drug. Our results are in line with another report from NHANES III showing that about $50 \%$ of all people with a diagnosis of hypertension (regardless of the actual blood pressure) were not receiving treatment.[50]

The decision not to treat might be a due to poor familiarity with the JNC guidelines, [51] to a risk/benefit evaluation tailored to the individual patient, or to patient preference.[52] Our data show that the risk profile is much more important in influencing treatment than the actual blood pressure levels. In fact, people with stage 2/3 hypertension but without risk factors or target-organ disease were treated less frequently than people with lower blood pressure with additional risk factors or target-organ diseases. The higher prevalence of treatment in people at higher risk (advanced age, cardiovascular diseases, and diabetes mellitus) suggests that the characteristics of the individual patient are a major determinant of the decision to treat. Although this finding might be an artefact due to the fact that people receiving treatment for hypertension are likely to have normal blood pressure levels and therefore not captured by our study, other data from different settings support this interpretation. A community-based study in a older population showed that hypertensive people with additional risk factors were more likely to receive antihypertensive medications, [53] while a prospective study in a family medicine setting found that treatment for hypertension was independent from the actual blood pressure readings.[54] Concomitant cardiovascular diseases were associated with increased use of antihypertensive in a nursing home population.[55] The explanation that physician's own clinical judgment might override guidelines' recommendation is also in accordance with data on compliance with guidelines on diabetes care.[56]

We found that, among people with a prescription and taking an antihypertensive drug at the time of the interview, the type of medication was not following the indication of the JNC VI. This failure of the JNC guidelines in influencing the type of therapy described has already been described in a study examining the effect of the fifth report of the JNC.[57] However, it must be noted that this is a cross-sectional study and we have no information on which drugs have previously been tried.

Our data show no association between the generalizability of the trials and the decision to prescribe an antihypertensive medication. This study is underpowered to rule out an association, but the comparison of the point estimates of the OR of being treated in the crude analysis and the adjusted model confirms the role of the clinical characteristics in physicians' adherence. In the crude analysis, where this baseline risk is not taken into account, people to whom the clinical trials are not generalizable are more likely to be treated. In the multivariable analysis taking into account the baseline risk, the direction of the association is reversed. The reason for this finding probably lies in the fact that clinical trials considered tend to exclude high risk people (see table 2), who are the most likely benefit from treatment and therefore to be treated in clinical practice.

Translating trial findings into clinical decision making is never an easy task, and generalizability is one of the factors that should be taken into account when trying to implement "evidence based" interventions. Other related factors are also likely to play a role. Patient's preference is one of these, and has more far-reaching implications than just treatment choice. The prescription of a drug that the patient deems effective may have a beneficial effect in and of itself, something that has been defined "therapeutic effect of patient preference".[58] While controlled clinical trials can avoid this problem by blinding the patients to the treatment they are receiving, in the clinical practice setting this is impossible. Furthermore, patients with strong preference are likely to refuse randomization, and this clearly affects generalizability. One possible solution is to use information coming from settings more similar to the clinical practice when making recommendations. For example, beside observational studies, valuable information can come from "pragmatic trials", that are performed in the real clinical practice, and aim to inform choices between treatments rather than to measure the benefit of a treatment under ideal circumstances.[59]

\section{Limitations}

The results of this study should be evaluated taking into account the limitations of our approach. First, people receiving an antihypertensive medication are more likely to have normal blood pressure, therefore were not in our sample. Although the proportion of people whose high blood pressure was controlled by anti-hypertensive drugs was relatively low (10\%), this bias potentially leads to an underestimation of the adherence to guidelines. However, the treatment rate in this population $(70 \%)$ is similar to that reported in another study in a different setting, in 
which the prevalence of treatment among people with known hypertension was 80\%.[60]

The diagnosis of hypertension and the decision on drug treatment were made before the blood pressure levels used in this study were measured. Therefore, the blood pressure at the time of the last physician's visit was not necessarily as high as at the moment of the study interview. The result would be an underestimation of the adherence rate. Although this bias cannot be discounted, the rate of treatment that we observed is similar to that observed in other studies.[61,62] Furthermore, blood pressure was measured at a single point in time, and there is the possibility that a regression to the mean effect have reduced the number of patients appropriate for the JNC VI guidelines. Another source of bias might come from people who were prescribed lifestyle modification, and whose blood pressure had increased to level requiring drug treatment at the time of the interview. Again, we would have underestimated the adherence rate.

We control only for only a few eligibility/exclusion criteria. It is probable that the proportion of people that would have been enrolled in the clinical trials we considered is actually much lower than we report. For example, in the SHEP trial only $2.7 \%$ of people screened were eligible to the first baseline visit. Of these, less than half was actually randomized. If people to whom the trials are generalizable were actually more likely to receive treatment, this misclassification would result in a spurious negative association between generalizability and treatment. On the contrary, if people excluded from the trial are more likely to receive drug treatment, we might underestimate the negative association between generalizability and adherence to guideline. Data from the literature show that the second scenario is more likely, with people with risk factors that lead to exclusion from the clinical trial being more likely to be treated.

Finally, the precision of our estimates was quite low, and the inferences that can be made on the basis of our data are limited by this lack of statistical power.

\section{Conclusion}

Guidelines on drug treatment of hypertension are based on evidence obtained in general on samples that are different from the target population with regard to important clinical characteristics. These differences may translate in a different baseline risk profile, and consequently with a different risk/benefit ratio of antihypertensive therapy.

Our data suggest a weak association between generalizability and adherence rate, although our findings are not statistically significant. We found that the individual risk profile influence role on physicians' decision to treat more than blood pressure levels. Differences in the risk profile between people enrolled in the studies on which clinical practice guidelines and the target population might affect the adherence rate.

\section{Competing interests}

None declared.

\section{Author's contributions}

$\mathrm{CP}$ conceived the study. Both authors participated equally in the study design, data analyses, writing and revision.

\section{References}

I. Committee to advise the public health service on clinical practice : Clinical practice guidelines: directions of a new program Edited by: FieldMJ and LohrKN. Washington, D.C., National Academy Press; 1990.

2. Grimshaw JM and Russel IT: Effect of clinical guidelines on medical practice. A systematic review of rigorous evaluation Lancet 1993, 342:1317-1322.

3. Thomson $R$, Lavender $M$ and Madhoc $R$ : How to ensure that guidelines are effective BMJ I995, 3 I I:237-242.

4. Shapiro DW, Lasker RD, Bindman AB and Lee PR: Containing costs while improving quality of care: the role of profiling and practice guidelines Annu Rev Public Health 1993, I 4:219-24I.

5. Lomas J, Anderson GM, Dominick-Pierre K, Vayda E, Enkin MW and Hannah W]: Do practice guidelines guide practice? The effect of a consensus statement on the practice of physicians $N$ Engl J Med 1989, 32 I: | 306-131I.

6. Woolf SH: Practice guidelines: a new reality in medicine. III. Impact on patient care Arch Intern Med 1993, I 53:2646-2655.

7. Hayward RS, Guyatt GH, Moore KA, McKibbon KA and Carter AO: Canadian physicians' attitudes about and preferences regarding clinical practice guidelines CMAJ 1997, I56:17151723.

8. Davis DA and Taylor-Vaisey A: Translating guidelines into practice. A systematic review of theoretic concepts, practical experience and research evidence in the adoption of clinical practice guidelines CMAJ 1997, I 57:408-4I6.

9. Cabana MD, Rand CS, Powe RS, Wu AW, Wilson MH, Abboud PA and Rubin HR: Why don't physicians follow clinical practice guidelines? A framework for improvement JAMA 1999, 282: |458-I465.

10. Christakis DA and Rivara FP: Pediatricians' awareness of and attitudes about four clinical practice guidelines Pediatrics 1998 , I 0 I:825-830.

II. Grol R, Dalhuijsen J, Thomas S, Veld C, Rutten G and Mokkink H: Attributes of clinical guidelines that influence use of guidelines in general practice: observational study $B M J 1998$, 3 1 7:858-86|.

12. Shekelle PG, Woolf SH, Eccles $M$ and Grimshaw J: Developing guidelines $B M J$ 1999, 3 I 8:593-596.

13. Colditz GA, Miller JN and Mosteller F: How study design affects outcomes in comparisons of therapy. I: Medical Stat Med 1989, 8:44I-454.

14. Mant D: Can randomised trials inform clinical decision about individual patients? Lancet 1999, 353:743-746.

15. McKee M, Britton A, Black N, McPherson K, Sanderson C and Bain C: Interpreting the evidence: choosing between randomised and non-randomised studies $B M J 1999,319: 312-315$.

16. Gurwitz JH, Col NF and Avorn J: The exclusion of the elderly and women from clinical trials in acute myocardial infarction JAMA 1992, 268:1417-1422.

17. Health National Institute of, National Heart Lung and Blood Institute and Program National High Blood PressureEducation: The sixth report of the Joint National Committee on prevention, detection, evaluation, and treatment of high blood pressure Washington, NIH Publication; 1997.

18. Frohlich ED: Recommendations for blood pressure determination by sphygmomanometry Ann Intern Med 1988, 109:612.

19. Perloff D, Grim C, Flack J, Frohlich ED, Hill M, McDonald M and Morgenstern BZ: Human blood pressure determination by sphygmomanometry Circulation 1993, 88:2460-2470. 
20. Rothman $\mathrm{KJ}$ and Greenland S: Precision and validity in epidemiologic studies Modern Epidemiology Volume 2. Edited by: RothmanKJ and GreenlandS. Philadelphia, PA, Lippincott, Williams \& Wilkins; 1998: II5-134.

21. Analytic and reporting guidelines: the Third National Health and Nutrition Examination Survey, NHANES III (1988 - 1994) Hyattsville, MD, National Center for Health Statistics, Centers for Disease Control and Prevention; 1996.

22. MacMahon SW, Cutler JA, Furberg CD and Payne GH: The effects of drug treatment for hypertension on morbidity and mortality from cardiovascular disease: a review of randomized controlled trials Prog Cardiovasc Dis 1986, 29:99-I I8.

23. Psaty BM, Smith NL, Siscovick DS, Koepsell TD, Weiss NS, Heckbert SR, Lemaitre RN, Wagner EH and Furberg CD: Health outcomes associated with antihypertensive therapies used as first-line agents: a systematic review and meta analysis. JAMA 1997, 277:739-745.

24. Multiple risk factor intervention trial. Risk factor changes and mortality results. Multiple Risk Factor Intervention Trial Research Group JAMA 1982, 248: I 465-I 477

25. Wolff FW and Lindeman RD: Effects of treatment in hypertension. Results of a controlled study J Chronic Dis 1966, 19:227-240.

26. Sprackling ME, Mitchell JR, Short AH and Watt G: Blood pressure reduction in the elderly: a randomised controlled trial of methyldopa $B M]$ I 198I, 283: II I I-II 53 .

27. Cardiovascular risk and risk factors in a randomized trial of treatment based on the beta-blocker oxpreonolol: the International Prospective Primary Prevention Study in Hypertension (IPPPSH). The IPPPSH Collaborative Group J Hypertens 1985, 3:379-392.

28. Prevention of stroke by antihypertensive drug treatment in oler persons with isolated systolic hypertension: final results of the Systolic Hypertension in the Elderly Program (SHEP). SHEP Cooperative Research Group. JAMA I99I, 265:32553264.

29. Medical Research Council trial of treatment of hypertension in older adults: principal results. Medical Research Council Working Party BMJ 1992, 304:405-4I2.

30. Dahlöf B, Lindholm LH, Hansson L, Scherstén B, Ekbom T and Wester PO: Morbidity and mortality in the Swedish Trial in Old Patients with Hypertension (STOP-Hypertension). Lancet 199|, 338: | 28I-1285.

31. Kuramoto K, Matsushita S, Kuwashima I and Murakami M: Prospective study on the treatment of hypertension in the elderly. Jpn Heart J 198I, 22:75-85.

32. Control of moderately raised blood pressure. Report of a cooperative randomized controlled trial BMJ 1973, 3:434-436.

33. Effect of antihypertensive treatment on stroke recurrence. Hypertension-Stroke Cooperative Study Group JAMA 1974, 229:409-418.

34. Effects of treatment on morbidity in hypertension. I: results in patients with diastolic blood pressures averaging 115 through $129 \mathrm{mmHg}$. Veterans Administration Cooperative Study Group on Antihypertensive Agents JAMA 1967, 202: 1028-1034.

35. Effects of treatment on morbidity in hypertension. II: results in patients with diastolic blood pressure averaging 90 through II $4 \mathrm{~mm} \mathrm{Hg}$. Veterans Administration Cooperative Study Group on Antihypertensive Agents JAMA 1970 213:1143-1152.

36. Evaluation of drug treatment in mild hypertension: VANHLBI feasibility trial. Plan and preliminary results of a twoyear feasibility trial for a multicenter intervention study to evaluate the benefits versus the disadvantages of treating mild hypertension. Prepared for the Veterans Administration-National Heart, Lung, and Blood Institute Study Group for Evaluating Treatment in Mild Hypertension Ann N Y Acad Sci 1978, 304:267-292.

37. Five-year findings of the hypertension detection and followup program. I. Reduction in mortality of persons with high blood pressure, including mild hypertension. Hypertension Detection and Follow-up Program Cooperative Group JAMA 1979, 242:2562-257|.

38. Carter $A B$ : Hypotensive therapy in stroke survivors Lancet I 970, I:485-489.
39. Amery A, Birkenhager W, Brixko P, Bulpitt C, Clement D, Deruyttere M, De Schaepdryver A, Dollery C, Fagard R and Forette F: Mortality and morbidity results from the European Working Party on High Blood Pressure in the Elderly trial Lancet 1985, I:1347-1354

40. MRC trial of treatment of mild hypertension: principal results. Medical Research Council Working Party BMJ I985, 291:97-104.

41. Coope J and Warrander TS: Randomised trial of treatment of hypertension in elderly patients in primary care $B M J 1986$, 293: ||45-II5|

42. The Australian therapeutic trial in mild hypertension. Report by the Management Committee Lancet 1980, I:I26I1267.

43. Treatment of mild hypertension: results of a ten-year intervention trial. The US Public Health Service Hospital Cooperative Group Hypertension 1977, 25(suppI I):128-1105.

44. Hegeland A: Treatment of mild hypertension: a five year controlled drug trial. The Oslo study Am J Med 1980, 69:725-732.

45. Collins R, Peto R, MacMahon S, Hebert P, Fiebach NH, Eberlein KA Godwin NH, Qizilbash N, Taylor JO and Hennekens CH: Blood pressure, stroke, and coronary heart disease Lancet 1990, 335:827-838.

46. Glasziou $P$ and Irwig $L:$ An evidence based approach to individualising treatment $B M J$ I995, 3 I I: I356-1359.

47. Linjer $E$ and Hansson L: Underestimation of the true benefits of antihypertensive treatment: an assessment of some important sources of error J Hypertens 1997, I 5:22 I-225.

48. Carbonin P, Pahor M, Bernabei R and Sgadari A: Is age an independent risk factor of adverse drug reaction in hospitalized medical patients? J Am Geriatr Soc 1991, 39: 1093-1099.

49. Burt VL, Whelton P, Roccella EJ, Brown C, Cutler JA, Higgins M, Horan MJ and Labarthe D: Trends in the prevalence, awareness, treatment and control of hypertension in the adult US population: data from the health examination surveys, 1960 to 199 I Hypertension 1995, 26:60-69.

50. Hyman DJ and Pavlik VN: Self-reported hypertension treatment practices among primary care physicians: blood pressure thresholds, drug choices, and the rule of guidelines and evidence-based medicine Arch Intern Med 2000, 160:228I-2286.

5I. McAlister FA, O'Connor AM, Wells G, Grover SA and Laupacis A: When should hypertension be treated? The different perspectives of Canadian family physicians and patients. CMAJ 2000, 163:403-408.

52. Di Bari M, Salti F, Nardi M, Pahor M, De Fusco C, Tonon E, Ungar A, Pini R, Masotti $G$ and Marchionni N: Undertreatment of hypertension in community-dwelling older adults: a drug utilization study in Dicomano, Italy J Hypertens 1999, 17:1633-1640.

53. Beaulieu MD, Dufresne $L$ and LeBlanc $D$ : Treating hypertension: are the right drugs given to the right patients? Can Fam Physician 1998, 44:294-298.

54. Gambassi G, Lapane K, Sgadari A, Landi F, Carbonin P, Hume A, Lipsitz L, Mor V and Bernabei R: Prevalence, clinical correlates, and treatment of hypertension in elderly nursing home residents. SAGE (Systematic Assessment of Geriatric drug use via Epidemiology) Study Group Arch Intern Med 1998, I 58:2377. 2385

55. Mottur-Pilson C, Snow V and Bartlett K: Physician explanations for failing to comply with "best practices" Eff Clin Pract 200I, 4:207-2/3.

56. Siegel $D$ and Lopez J: Trends in antihypertensive drug use in the United States: do the JNC V recommendations affect prescribing? Fifth Joint National Commission on the Detection, Evaluation, and Treatment of High Blood Pressure JAMA 1997, 278: 1745-1748.

57. McPherson K, Britton AR and Wennberg JE: Are randomized trials controlled? Patient preference and unblind trials $J R$ Soc Med 1997, 90:652-656.

58. Roland $T$ and Torgerson $D$ J: What are pragmatic trials? $B M$ 1998, 3 | 6:285

59. Joffres MR, Ghadirian P, Fodor JG, Petrasovits A, Chockalingam $A$ and Hamet $P$ : Awareness, treatment, and control of hypertension in Canada Am J Hypertens 1997, I0: 1097- I 102.

60. Burt VL, Whelton P, Roccella EJ, Brown C, Cutler JA, Higgins M, Horan MJ and Labarthe D: Prevalence of hypertension in the US adult population. Results from the Third National Health 
and Nutrition Examination Survey, 1988-1991 Hypertension 1995, 25:305-313.

61. Klungel OH, Stricker BH, Paes AH, Seidell JC, Bakker A, Vok Z, Breteler MM and De Boer A: Excess stroke among hypertensive men and women attributable to undertreatment of hypertension Stroke 1999, 30:1312-1318.

62. Petrovitch $\mathrm{H}$, Byington R, Bailey G, Borhani P, Carmody S, Goodwin L, Harrington J, Johnson HA, Johnson P and Jones M: Systolic Hypertension in the Elderly Program (SHEP). Part 2: screening and recruitment Hypertension 199|, 17(suppl 3):| I 6-I23.

\section{Pre-publication history}

The pre-publication history for this paper can be accessed here:

http://www.biomedcentral.com/1471-2458/3/24/prepub

Publish with Bio Med Central and every scientist can read your work free of charge

"BioMed Central will be the most significant development for disseminating the results of biomedical research in our lifetime. "

Sir Paul Nurse, Cancer Research UK

Your research papers will be:

- available free of charge to the entire biomedical community

- peer reviewed and published immediately upon acceptance

- cited in PubMed and archived on PubMed Central

- yours - you keep the copyright

Submit your manuscript here:

http://www.biomedcentral.com/info/publishing_adv.asp 